\title{
O discurso curricular da proposta para BNC da formação de professores da educação básica
}

\author{
The curricular discussion of the proposal for BNC
}

on the training of basic education teachers

\section{El discurso curricular de la propuesta para BNC}

de la formación docente de la educación básica

\section{ISABEL MARIA SABINO DE FARIAS*}

Universidade Estadual do Ceará, Fortaleza, CE. Brasil.

\begin{abstract}
RESUMO: Este artigo examina a Proposta para Base Nacional Comum da Formação de Professores da Educação Básica, texto produzido na gestão do ex-presidente Michel Temer, encaminhada ao Conselho Nacional de Educação (CNE) em dezembro de 2018 e recolhido pelo Ministério da Educação no atual governo. Argumentos como professores bem preparados fazem a diferença no desempenho discente e a universidade não sabe formar professores conforma o consenso discursivo subliminar sob o qual se ergue a visão sistêmica da formação de professores neste documento, que assume o desenvolvimento de competências como referencial básico.
\end{abstract}

Palauras-chave: Formação de professores. Educação básica. BNCC.

Discurso curricular. Competências profissionais.

\begin{abstract}
This article examines the Proposal for a Common Core for Teacher Training in Basic Education, a text produced in the term of former President Michel Temer, sent to the National Education Council (CNE) in December 2018 and retracted by the Ministry of Education in the current government. Arguments as well-prepared teachers make a difference in student performance and the university does not know how to train teachers conforms to the subliminal discursive
\end{abstract}

* Pedagoga. Doutora em Educação. Professora do Centro de Educação e do Programa de Pós-Graduação em Educação da Universidade Estadual do Ceará. Coordenadora do Observatório sobre Desenvolvimento Profissional Docente e Inovação Pedagógica. Líder do grupo de pesquisa Educação, Cultura Escolar e Sociedade (EDUCAS/CNPq). E-mail: <isabelinhasabino@yahoo.com.br>. 
consensus under which the systemic vision of teacher education is raised in this document, which assumes the development of skills as a basic reference.

Keywords: Teacher training. Basic education. BNCC. Curricular discussion. Professional skills.

RESUMEN: Este artículo examina la propuesta para la Base Nacional Común de la Formación de Maestros de la Educación Básica, un texto producido en la administración del expresidente Michel Temer, derivado al Consejo Nacional de Educación (CNE) en diciembre de 2018 y recopilado por el Ministerio de Educación en el gobierno actual. Argumentos como "maestros bien preparados marcan la diferencia en el rendimiento de los estudiantes", y "la universidad no sabe capacitar a los docentes" refuerzan el consenso discursivo subliminal en el que se plantea la visión sistémica de la formación docente en este documento, que toma el desarrollo de competencias como marco básico.

Palabras clave: Formación de profesores. Educación básica. BNCC. Discurso curricular. Competencias profesionales.

\title{
Introdução
}

\begin{abstract}
Se nem todo momento será julgado oportuno para dizer a verdade, sobretudo quando amarga e dura, não se poderá esperar ocasião para restabelecê-la, o que é dever de todos, quando desfigurada, e proclamá-la sem rebuços e meias palavras (MAIS UMA VEZ CONVOCADOS, 1959, p.3).
\end{abstract}

$\mathrm{R}$ etomo as palavras iniciais do Manifesto de educadores brasileiros, escrito por Fernando de Azevedo, para dizer da necessidade e da urgência de problematização do discurso engendrado, de modo orquestrado e a 'toque de caixa', sobre a formação de professores na reforma curricular em curso no Brasil nessa segunda década do século XXI. Mobilizado por este desafio, este artigo objetiva examinar o documento "Proposta para Base Nacional Comum da Formação de Professores da Educação Básica" (BRASIL, 2018), texto produzido durante a gestão do ex-presidente Michel Temer, encaminhado ao Conselho Nacional de Educação (CNE) em dezembro de 2018 e, posteriormente, recolhido pelo Ministério da Educação (MEC) no atual governo.

A “Proposta para Base Nacional Comum da Formação de Professores da Educação Básica”, um componente da Política Nacional de Formação de Professores (PNFP), apresentada pelo MEC em 18 outubro de 2017, insere-se no quadro das ações da contrarreforma da 
educação básica (AGUIAR, 2018), processo encaminhado, desde o impeachment do governo de Dilma Rosselff ${ }^{1}$, de maneira intempestiva e rompendo com processos coletivos de discussão e negociação legalmente constituídos, o que se materializou por interesses diversos, comprometendo aspectos e decisões democráticas, situação essa que é evidenciada, por exemplo, na própria elaboração e discussão da Base Nacional Comum Curricular (BNCC).

A princípio pode parecer estranho - inquirir um documento cujo texto foi colocado em suspeição pelo próprio órgão que o elaborou e submeteu à apreciação de seus pares, a considerar que o CNE é uma instância colegiada integrante do Ministério da Educação, situação, porém, que requer maiores e sistemáticas reflexões, a fim de ser compreendido e desmitificado o que há por trás dessas ações, que têm em si interesses diversos e contraditórios.

Seria este um texto em desacordo com as ideias postuladas pelo atual governo? $\mathrm{Ou}$ seu recolhimento é apenas um indicativo de uma permanência patológica das políticas públicas nacionais - a descontinuidade? É fato que movimentos diversos atravessam a produção do discurso curricular no atual contexto de contrarreforma, sobretudo em relação aos professores, do qual a "Proposta para Base Nacional Comum da Formação de Professores da Educação Básica" faz parte, compondo o campo de disputa aí instalado, o que, por si só, reforça a necessidade de escrutinar esse documento, ainda pouco explorado, apesar de sua relevância para a agenda educacional brasileira. Entendo que o seu recolhimento do CNE pelo MEC favoreceu, de alguma maneira, esse silenciamento, ao deslocar a atenção sobre o teor desse texto acerca do que deve ser a formação dos professores no País. A mensagem subliminar que seu recolhimento emitiu, de que ele estaria em desacordo com as ideias postuladas pelo atual governo, não se sustenta, seja pelos artífices que lhe deram vida, seja pelas posições que assume, o que nos convoca a enxergá-lo como um documento que, a seu modo, efetivamente fala, pois guarda indícios dos acontecimentos e concepções que lhe foram adjacentes, indícios reveladores de sua tessitura social (FARIAS; BEZERRA, 2011).

Que política de formação de professores se materializa na "Proposta para Base Nacional Comum da Formação de Professores da Educação Básica"? Em que se fundamenta? A que atores sociais e expectativas atende? Há avanços? Que aspectos manifestam controvérsia com as pesquisas na área e a luta dos educadores? Enfim, o que ela revela sobre a concepção de formação de professores e o possível desenho de uma política estruturante para essa área no Brasil? Possibilidade, diga-se de passagem, que não é meramente especulativa, a considerar a existência material desse texto, apresentado, nas palavras de Katia Smole, Secretária de Educação Básica do MEC a época, como “versão zero". Em sendo assim, seu recolhimento faz pressupor que uma versão 'revista e ampliada' (bem ao gosto da lógica editorial dos dias de hoje) deve estar a caminho².

As inquietações que movem o exame desse documento encontram apoio, portanto, no reconhecimento de que o país vive um tempo de graves retrocessos de conquistas democráticas, o qual tem sua materialização mais visível na disputa entre uma política 
educacional constituída por ampla negociação em diferentes fóruns sociais, e a imposição de uma política de interdição de qualquer diálogo (ANPED, 2018). É o que expressam fatos como a dissolução do Fórum Nacional de Educação (FNE), que restringiu a participação da sociedade civil e concentrou na figura do ministro da pasta a responsabilidade de decidir quem entra e quem sai de sua composição, bem como as sucessivas reestruturações da Comissão Bicameral da Base Nacional Comum do CNE, responsável por acompanhar e contribuir com o MEC na elaboração de documento sobre direitos e objetivos de aprendizagem e desenvolvimento, visando o cumprimento de estratégias das Metas 2 e 3 do Plano Nacional de Educação (PNE). Não são poucos e nem inexpressivos os sinais da imposição contínua de políticas sem debate por parte do MEC no atual governo, ação fortemente denunciada pela Associação Nacional de Pós-Graduação e Pesquisa em Educação (Anped), Associação Nacional pela Formação dos Profissionais da Educação (Anfope), Associação Brasileira de Currículo (ABdC) e demais entidades da área.

É no intento de contribuir com a reflexão em torno das tensões que circundam a formação de professores no contexto da BNCC que crivo minha atenção na "Proposta para Base Nacional Comum da Formação de Professores da Educação Básica", cuja análise ainda se encontra circunscrita a notícias opinativas e informativas em site e páginas do governo, informes em blogs autônomos e institucionais de empresas, além de cartas, notas e manifestos de repúdio de entidades organizadas da sociedade civil. Para tanto, tomo como ponto de partida o texto da referida proposta, cujo exame dialoga com produções recentes em torno do assunto, bem como por entidades representativas da área como a Anped, Anfope, ABdC, Anpae (Associação Nacional de Política e Administração da Educação), Abrapec (Associação Brasileira de Pesquisa em Educação em Ciências), Cedes (Centro de Estudos Educação e Sociedade), Forumdir (Fórum Nacional de Diretores de Faculdades, Centro de Educação ou Equivalentes das Universidades Públicas Brasileiras), FINEDUCA (Associação Nacional de Pesquisadores em Financiamento da Educação), CNTE (Confederação Nacional dos Trabalhadores em Educação), entre outras.

Para este escrito, considerando as limitações que sua abrangência implica, destaco alguns argumentos sistematizados a partir da "Proposta para Base Nacional Comum da Formação de Professores da Educação Básica", formulados no intuito de problematizar as intenções proclamadas neste documento e instigar que outras produções possam ser constituídas e consolidadas com suporte em algumas das discussões aqui delineadas.

\section{"A ocasião trai a intenção"}

A ênfase na celeridade dos encaminhamentos dos assuntos educacionais é uma tônica nas ações envidadas na cena brasileira nesses três últimos anos, movimento que tem produzido a desconstituição de processos democráticos amplos de participação na 
formulação e implementação de suas políticas. Os anúncios públicos feitos pelo MEC, em outubro de 2017 e em dezembro de 2018, respectivamente, sobre a Política Nacional de Formação de Professores (PNFP) e a Proposta para a Base Nacional Comum da Formação dos Professores da Educação Básica (PBNCFP) ilustram esta tendência.

A publicização da Política Nacional de Formação de Professores se sucedeu em meio a escândalos de corrupção nos altos escalões da gestão pública; retrocessos nas regras de fiscalização do trabalho escravo; greves de professores; acidentes aéreos, entre outros acontecimentos que repercutiram sobre o governo ilegítimo instalado em 2016. A apresentação desta política neste contexto ressoou e se consolidou, para muitos, como uma cortina de fumaça política, uma aposta de que a importância da temática forneceria uma trégua na pressão social em torno do governo a época.

Trata-se, no meu entendimento, de um texto enredado pelas disputas políticas mais amplas, bem como aquelas internas ao MEC, decorrentes das sucessivas reconfigurações de poder nesse âmbito nos últimos três anos. Este movimento propiciou o alargamento da presença de representantes do setor empresarial e industrial, hábeis na costura de articulações importantes, na construção de "sentidos" e na difusão de "hegemonias de parâmetros globalizantes e mercadológicos" (LIMA VERDE, 2015, p.86), que, por diferentes vias, matizam o discurso que conforma a PNFP.

Causou estranheza a divulgação da PNFP por meio apenas de slides, o que se mantém 22 meses após seu anúncio público, situação que é bastante preocupantee, ao mesmo tempo, revela e explicita uma série de retrocessos na história da educação do País, que se sucedem em decretos posteriores do atual governo, com ataques constantes nas diversas conquistas e avanços historicamente concretizados. A estrutura e conteúdo das 21 lâminas destacam premissa, cenário, diagnóstico, princípios, dimensões e linhas de ação da política apresentada. Um texto ainda alinhavado, um traçado panorâmico é o que o MEC disponibilizou para a sociedade brasileira como 'a nova' Política Nacional de Formação de Professores.

A ideia de uma "base nacional de formação docente" se explicita com todas as letras nessa nova PNFP, aparecendo, no slide que lhe faz referência, acompanhada de três indicativos: “Norteará o currículo de formação de professores; Proposta em elaboração a ser articulada com estados, municípios, instituições formadoras e CNE; Consulta pública início de 2018" (BRASIL, 2017, slide 12). Uma indicação pontual, mas que não é inocente e deve sim preocupar, pois, conforme problematizado por oito entidades científicas ${ }^{3} \mathrm{da}$ área da educação e da formação de professores em manifesto publicado no sítio da Anped em 20 de outubro de 2017:

Se está em elaboração uma Base Nacional de Formação de Professores quem são os interlocutores desse documento que será apresentado para consulta pública em 2018? De que modo essa Base impactará a implantação, em curso, da Resolução no. 2/2015 do CNE? Quais seriam as prioridades dessa base, que parece estar sendo formulada desconsiderando as condições concretas enfrentadas pelos docentes em seu dia a dia profissional? Que critérios presidiriam essa proposta, que não dialoga com 
entidades da área ou com as questões que vêm sendo estudadas pelos profissionais que nela atuam e a ela se dedicam? Num momento em que questionamentos múltiplos são feitos à proposta de unificação curricular na Educação Básica, preocupa ver a proposta de mais uma base, que, muito provavelmente, enfrentará os mesmos problemas que enfrenta a centralização curricular na Educação Básica, incapaz de reduzir desigualdades ou de promover melhoria da qualidade do ensino - e nesse caso, da formação - como afirma o texto apresentado. Cabe ainda reafirmar que nãoé dessa forma impositiva que se institui a política nacional de formação de professores prevista no Plano Nacional de Educação, hoje ameaçado (MANIFESTAÇÃO, 2017).

As inquietações evidenciam a ausência de diálogo com as universidades públicas, com as entidades acadêmicas do campo educacional e as entidades representativas de professores e estudantes. Sua elaboração silenciosa e em petit comitê, entre outros aspectos, desconsiderou o processo democrático de discussão e negociação constituído nos últimos anos na formulação da política educacional brasileira e materializado no Plano Nacional de Educação 2014-2024 (Lei no 13.005/2014).

O PNE estabelece diretrizes visando a uma maior organicidade para a educação nacional, abrangendo metas e estratégias que articulam a educação básica e a educação superior, as quais, conforme anota Dourado (2015, p. 301), "incidem nas bases para a efetivação de uma política nacional de formação dos profissionais da educação e foram consideradas nas diretrizes curriculares nacionais para a formação inicial e continuada dos profissionais do magistério". O autor, a época Conselheiro do CNE, refere-se às Diretrizes Curriculares Nacionais para a Formação Inicial em nível superior (cursos de licenciatura, cursos de formação pedagógica para graduados e cursos de segunda licenciatura) e para a Formação Continuada, aprovada por meio da Resolução nº 2/2015 daquele Conselho. A indicação é, a meu ver, clara: o País já conta com diretrizes definidas para nortear a política nacional de formação dos profissionais da educação, bem como o currículo de formação de professores. Diretrizes que, a despeito das manobras efetuadas pelo atual governo (e embora sua revogação ainda continue sendo orquestrada), encontram-se em vigor e expressam o consenso edificado com ampla participação da sociedade em torno dos aspectos constituintes e constitutivos da base comum para a formação de professores.

A ausência de um documento sistematizado, e não somente slides, após quase dois anos de seu anúncio, tem dificultado o debate social e o aprofundamento das ideias que estão a fundamentar a Política Nacional de Formação de Professores, da mesma forma que o recolhimento da "Proposta para Base Nacional Comum da Formação de Professores da Educação Básica" desmobilizou sua análise. Ademais, considerando o interstício temporal transcorrido, parece oportuno indagar sobre o tipo de articulação entre estados, municípios, instituições formadoras e CNE se está operando e, principalmente, acerca do indicativo de realização de uma "consulta pública", afinal, julho de 2019 já chegou.

A considerar a intenção e o gesto até aqui explicitado, o que se evidencia é que, embora apresentada como "revolucionária" pelo MEC, a PNFP, assim como seu 
componente "Proposta para Base Nacional Comum da Formação de Professores da Educação Básica”, mais contribuiu para avolumar críticas. O que há de revolucionário na ausência do diálogo? Não seriam as práticas verticalizadas e autoritárias recorrentes na história social? Revolucionário para quem e em qual direção? O fazer-se apartado da discussão pública, ao expressar a verticalização da formulação desta política, centralizada no MEC e entre alguns pares confiáveis, é sintomática do argumento de que "a ocasião trai a intenção".

\section{Uma "versão zero" com script fechado}

A "Proposta para Base Nacional Comum da Formação de Professores da Educação Básica" está materializada em um texto com 65 páginas, que, além da apresentação e bibliografia, compõe-se de quatro partes: I - Estado da Arte da Formação de Professores; II - Visão Sistêmica da Formação; III - Matriz de Competências Profissionais; IV - Limites e Indicações. O discurso de que o conhecimento é o novo capital do desenvolvimento social e econômico sustentável, razão pela qual a educação ocupa uma "posição estratégica" nesta agenda, é a ideia chave que atravessa este documento. A avaliação dos resultados, ressaltada como uma evidência da "revalorização da escola e do conhecimento", serve de mote para o estabelecimento de correlações diretas entre o professor e a aprendizagem discente, esta última reduzida a noção de desempenho, algo que é bastante presente e que corrobora com os discursos e reais interesses da agenda que constitui e materializa as avaliações externas.

A compreensão desse discurso, por óbvio, não se descola de sua tessitura social, emblematicamente refletida nos artífices que lhe deram materialidade enquanto proposta produzida em um dado contexto histórico, precisamente sob os auspícios do governo ilegítimo instalado em 2016, momento em que se avoluma a presença de segmentos privados organizados da sociedade civil em diversos setores da gestão pública, em especial no âmbito do MEC. A composição da equipe de autores responsáveis pela elaboração da "Proposta para Base Nacional Comum da Formação de Professores da Educação Básica" não nos permite pensar de outra maneira. Os seis profissionais envolvidos nesta tarefa - Maria Alice Carraturi Pereira (Hélade Consultoria em Educação), Guiomar Namo de Mello (Fundação Victor Civita), Bruna Henrique Caruso (SEB/MEC), Fernando Luiz Abrucio (FGV), Catarina Ianni Segatto (Eaesp/CEAPG) e Lara Elena Ramos Simielli (Eaesp/FGV) (BRASIL, 2018) - registram trajetórias marcadas por atuação na área da administração, da educação à distância e no setor empresarial e educacional privado.

Não é de admirar que esta equipe de especialistas tenha adotado como referência a análise da empresa de consultoria empresarial estadunidense McKinsey \& Company para erigir as premissas a partir das quais constituíram o discurso da referida proposta, 
quais sejam: a) a origem socieconômica do aluno pode ser compensada pela ação da escola; b) dentre os fatores controláveis pela escola, o professor é o que mais pesa na determinação do desempenho do aluno; c) professores bem preparados fazem diferença significativa no desempenho dos alunos, independentemente do seu nível socioeconômico (BRASIL, 2018, p. 5). A responsabilização da escola e do professor pela melhoria da aprendizagem do estudante, subsumida ao desempenho nas avaliações externas, é o que aqui se sobressai ${ }^{4}$.

Premissas que conformam o discurso de que é preciso melhorar a qualidade dos professores e delineiam a formação desse profissional como pedra-de-toque da reforma curricular que ora configura a política educacional em curso. Para firmar a exigência de adequação das normas, currículos e programas de formação inicial e continuada de professores à BNCC a "Proposta para Base Nacional Comum da Formação de Professores da Educação Básica" adota um tom impositivo, advertindo sobre sua constitucionalidade ao referir-se ao que dispõe a LDB/96 (Art. 61, §8º) e a Resolução do CNE/CP no 02/2015. Em várias passagens da Proposta essa expectativa de alinhamento é registrada de modo categórico, a exemplo da asserção: "é necessário, até mesmo obrigatório” (BRASIL, 2018, p. 7). Este indicativo projeta, inclusive, a possibilidade de "atualização" das Diretrizes Curriculares Nacionais (DCN), aprovadas pelo CNE, para a formação inicial em nível superior e para a formação continuada de professores da educação básica, tendo em vista seu enquadramento à "visão sistêmica" e ao arcabouço conceitual das "competências profissionais" que a proposta supracitada postula.

Importa anotar que a Resolução CNE/CP nํ 2/2015 tem sido alvo de ampla defesa por parte da sociedade civil organizada e entidades da área educacional, que a reconhecem como resultante de intenso processo participativo, contemplando avanços para a formação de profissionais da educação e para uma sociedade mais justa e democrática (ANPED 2019). Este, entretanto, não é o entendimento do MEC, que percebe nessa resolução elementos que restringem a implementação da BNCC, posição que tem produzido ações no sentido de revogar sua validade ou mesmo adiar os prazos instituídos para a observância do que define as DCN da formação de professores.

Um episódio desse embate encontra-se na consulta encaminhada pela então presidente da Comissão Bicameral de Formação Inicial e Continuada de Professores do CNE, Malvina Tania Tuttman, solicitando manifestação, de oito entidades ${ }^{5}$ nacionais do campo da educação, sobre a manutenção ou alteração do prazo da Resolução CNE/CP no 2/2015. A consulta, conforme termos do Ofício-Circular nº 2/2018/SE/CNE/CNE-MEC, de 18 de junho de 2018, "se justifica na medida em que o CNE recebeu recentemente algumas consultas institucionais com vistas a considerar, mais uma vez, a ampliação de prazo para a implantação da referida Resolução, prevista para 1/7/2018". O excerto fornece pistas da disputa política e dos processos de resistência em torno da BNCC e de seus desdobramentos na formação de professores, especialmente aqueles travados no âmbito interno 
entre CNE e MEC. Vale lembrar que nesse momento o MEC, “sob nova administração, ao delinear sua política, adota 'medidas de políticas' que, no limite, apresentam um forte viés privatista favorecendo interesses do mercado" (AGUIAR, 2018, p.8).

Este viés se explicita na "Proposta para Base Nacional Comum da Formação de Professores da Educação Básica" desde a composição da equipe de especialistas responsáveis por sua formulação, em caráter privado e sem escuta das entidades, comunidade acadêmica e professores (principais interessados!) da "versão zero" deste documento. Movimento que encontra eco no alerta de Macedo (2018, p. 31), ao chamar atenção para a perda do "caráter público das políticas educacionais, não apenas pela parceria com instituições privadas, mas pela assimilação de seus modos de gestão".

A noção de competência profissional, debitária do viés neoliberal, impregna a visão sistêmica esboçada para a formação de professores, assim como a matriz de competências profissionais ali desenhada. Competência compreendida como "organizadores de conteúdos curriculares a serem trabalhados nas instituições de ensino" (BRASIL, 2018, p.41), concepção que atribui às instituições formadoras papel meramente operacional. Ao estabelecer uma matriz a Proposta elenca competências que o futuro professor necessita desenvolver para ingressar, permanecer e progredir na carreira, conforme sua visão sistêmica e que revela em si dimensões que estão bastante presentes e que se evidenciam em uma retomada de aspectos do tecnicismo, pois a autonomia e a criticidade da docência não se expressam com maior destaque no texto. Uma matriz caracterizada pela descrição comportamental do que o professor deve demonstrar que aprendeu, portanto, como "uma descrição de onde chegar" (MACEDO, 2018, p.32). Um script fechado, pois com uma lógica homogeneizante e focada nos resultados, que não deixa margem para pensar a formação para a docência numa perspectiva larga e que considere a complexidade do ensinar, a diversidade dos contextos de trabalho, a pluralidade social dos discentes com os quais o professor lida e, sobretudo, para promover um desenvolvimento que valorize efetivamente esse profissional.

O termo script evoca a ideia de roteiro, o qual, no caso da Proposta em análise, se expressa de modo acrítico, resumido e com interesses neoliberais não expostos claramente, mas que estão manifestos, inclusive, no modo como esse documento foi elaborado, sem valorizar as discussões anteriores e sem de fato representar os anseios e as necessidades dos mais diversos profissionais que desenvolvem, pesquisam e constituem a educação do País. Por sua vez, o termo versão, que se refere a interpretação, conota à expressão "versão zero" a ideia de interpretação preliminar, um esboço aberto. Não me parece, porém, ser este o espírito do texto da "Proposta para Base Nacional Comum da Formação de Professores da Educação Básica”, pois, embora recolhido pelo MEC, as ações e decisões do atual governo nesses primeiros meses de gestão não indicam desacordo com o discurso da competência, sua chave teórica fundante. 


\section{Os professores - mais uma vez desqualificados}

A "Proposta para Base Nacional Comum da Formação de Professores da Educação Básica" retoma o argumento da melhoria da qualidade da educação, tão caro às reformas educacionais, especialmente aquelas concebidas nas últimas décadas do século XX e em franco desenvolvimento nestes dois decênios do século XXI.

Digo retoma porque este argumento, como anotam Cabral Neto e Rodriguez (2007), está na base do Projeto Principal de Educação(PPE), posteriormente do Projeto Regional de Educação para a América Latina e Caribe (Prelac), iniciativas internacionais edificadas pela Unesco, Cepal e OEA, desde o final dos anos de 1970, voltadas para o aprimoramento dos sistemas educacionais. Se na década de 1980 o foco das políticas orquestradas a partir do PPE voltou-se para a "dimensão quantitativa da educação" em vista do entendimento do "desenvolvimento social como melhoria da qualidade de vida das pessoas", na década de 1990 a ênfase recai sobre a qualidade da educação pela via da "qualidade da gestão dos sistemas educativos", prevalecendo a ideia da educação como "principal instrumento para o desenvolvimento produtivo com equidade" (Ibidem, 2007, p.23). Os autores supracitados ainda destacam que, no decorrer das várias fases dessa política, o conceito de qualidade "evoluiu [...] passando de uma referência à gestão para outra mais vinculada às aprendizagens dos alunos, conseguindo-se com isso maior vinculação com a avaliação do rendimento acadêmico [...] (Ibidem). Uma agenda mundial que põe em movimento, em diferentes países, entre eles o Brasil, uma política educacional eivada por interesses neoliberais.

Insisto nessa digressão para realçar o argumento que abre esse tópico, lembrando que, se não é de hoje que os professores, pelo menos no plano retórico, são convocados nos processos de reforma, a perspectiva que se vislumbra na "Proposta para Base Nacional Comum da Formação de Professores da Educação Básica" da nova PNFP opera com uma imagem que desqualifica esses profissionais. Uma imagem que permeia todo o texto desse documento e está subliminarmente manifesta no excerto que segue:

\footnotetext{
A universalização do acesso à educação obrigatória no Brasil já alcançou o ensino fundamental e caminha para o ensino médio. É amplamente reconhecido, no entanto, que a qualidade das aprendizagens é muito insatisfatória e não mostra tendência de melhorar. Diante das evidências sobre o forte impacto que tem no desempenho dos alunos, a qualidade do trabalho do professor precisa ocupar um espaço relevante na agenda das políticas educacionais (BRASIL, 2018, p. 26, grifo meu).
}

A noção de aprendizagem encontra-se no centro do discurso configurado na Proposta. Sua associação e, por que não dizer, redução a noção de desempenho está claramente explicitada. Este documento, aliás, é marcado pelo uso indiscriminado e asséptico do termo aprendizagem e desempenho, tomados como sinônimos. A associação entre aprendizagem e desempenho explicita a forte vinculação a avaliação dos resultados, orientação 
claramente assumida na BNCC e tomada como referência na Proposta, usada recorrentemente para firmar a falta de qualidade dos professores.

A imagem de desqualificação que ela opera em relação aos professores desvela-se, ainda, no fato de que situa na qualidade de sua atuação, ou seja, na qualidade de sua prática de ensino, o problema da melhora da aprendizagem dos estudantes. Corrobora-se a advertência de Lopes (2018, p.26) acerca da não problematização da noção de qualidade da educação no âmbito do debate pedagógico em torno da BNCC, reduzida "a uma vaga noção de qualidade de ensino, de assimilação de conteúdos, ao cumprimento de expectativa de aprendizagem", enfim, a uma perspectiva político-pedagógica míope. É o que se verifica também na "Proposta para Base Nacional Comum da Formação de Professores da Educação Básica" ao tecer o corolário de que "professores bem preparados" fazem a diferença no desempenho dos alunos (BRASIL, 2018, p.5). Esta proposição-que expressa a ideia de que professores bem "preparados" são professores que ensinam melhor e, por conseguinte, são professores cujos alunos aprendem mais - nada tem de óbvia, mas muito tem a dizer da perspectiva linear e enviesada da "Proposta para Base Nacional Comum da Formação de Professores da Educação Básica".

Trata-se, sobretudo, de uma perspectiva que desconsidera as assimetrias regionais de um país continental como o Brasil e suas implicações na prática educativa escolar; que opta por desconfiar da qualidade do trabalho que os professores realizam e, como precisamente argumenta Lopes (2018, p.25), tende a escamotear “[...] a problemática de que a desigualdade social associada à educação não é decorrente de um registro intrinsecamente pedagógico". A autora ainda acrescenta que as desigualdades existentes no sistema decorrem, sobretudo, do "investimento diferenciado na carreira do professor e nas condições de trabalho nas escolas, nas condições de vida das famílias e nas condições de estudo dos alunos e alunas" (Ibidem).

Igualmente preocupante é o tom acusatório do discurso que impinge à universidade o desprestígio da profissão docente, pois, conforme o texto da "Proposta para Base Nacional Comum da Formação de Professores da Educação Básica", permanece a "ausência de um lugar ou uma instituição especificamente voltada para a formação de professores", fato que historicamente tem favorecido a "dissociação entre conhecimento científico e o conhecimento pedagógico" (BRASIL, 2018, p.14). Os argumentos edificados em torno dessa premissa buscam evidenciar, em última análise, que a universidade nunca soube o que fazer com a formação de professores, daí decorrendo sua marginalização na educação superior.

Ultrapassar a produção de um consenso discursivo de desqualificação do professor e da universidade como lócus da formação de professores é fundamental para a produção de uma política nacional de formação de professores que sustente uma base comum para a formação inicial e continuada dos professores da educação básica que valorize o magistério articulado a carreira, condições de trabalho e conhecimento (DOURADO, 2014), consubstanciando-se, por essa via, em componente efetivo da profissionalização docente. 


\section{A guisa de conclusão}

A mobilização social em defesa da educação pública, gratuita, democrática, laica, de qualidade para todo cidadão e cidadã e do Plano Nacional de Educação (PNE) como política de Estado tem se agigantado nesses últimos três anos, desde o impeachment de Dilma Rousseff, constituindo importante contraponto ao movimento de desmonte da política educacional brasileira. A formação do Fórum Nacional Popular (FNPE) e da Conferência Nacional Popular de Educação (Conape) como espaço e processo democrático e participativo de monitoramento e avaliação de políticas educacionais, ações decorrentes da desfiguração do FNE (Decreto Executivo de 26 de abril de 2017 e da Portaria nº 577, de 27 de abril de 2017), são emblemáticas dessa mobilização.

O posicionamento das entidades é de problematização e repúdio aos novos marcos regulatórios que se impõem sobre a educação básica e a educação superior, uma vez que a BNCC e os desdobramentos dela decorrentes, a exemplo da "Proposta para Base Nacional Comum da Formação de Professores da Educação Básica”, não expressam a concepção de base comum nacional construída pelo movimento dos educadores, conforme anota a professora Nilda Guimarães Alves, em artigo seminal publicado em 2017 e intitulado "Formação de docentes e currículos para além da resistência".

Ao retomar eventos históricos em torno da formulação do construto base comum nacional esta autora corrobora o entendimento exposto ao longo deste escrito, de que as DCN para a formação inicial e continuada de professores (Resolução CNE/CP no 02/2015) consubstanciam marco legítimo para a organização, gestão e regulação da formação de professores em âmbito nacional.

Lembra, ainda, que a ideia de base comum nacional foi produzida durante Encontro Nacional realizado em 1983, puxado pelo MEC, e que contou com participantes de toda a federação, visando discutir um currículo para a formação de professores no Brasil. A ideia era identificar elementos comuns de experiências curriculares diversas desenvolvidas por universidades, respeitando questões regionais e a constituição conjunta com a comunidade acadêmica. Nesse sentido, “a possibilidade de vir a ser 'nacional' só ocorreria após o surgimento de ideias 'comuns' a partir dos debates em torno dessas diversas experiências necessárias, em sua diversidade, e do estabelecimento de ideias, em comum, acerca do que é possível na formação" (ALVES, 2017, p.6).

A considerar a propositura original de base comum nacional do movimento dos professores brasileiros, bem como a paulatina incorporação de suas ideias nos anos que se seguem nos dispositivos legais da educação brasileira ${ }^{6}$, o que se assiste nos dias atuais, em especial na "Proposta para Base Nacional Comum da Formação de Professores da Educação Básica", é uma inversão do sentido histórico desse construto, no qual se sobreleva a noção de base nacional, mais alinhada às articulações discursivas da homogeneização, da eficácia e da avaliação. Uma proposta nessa direção não valoriza o professor; não torna a carreira atraente; 
não fortalece a formação pedagógica nas licenciaturas; não estabelece mecanismos coesos e pertinentes que promovam o desenvolvimento docente desde a inserção profissional, entre outros desafios que permanecem e nos convocam a resistir, sempre e criativamente.

Recebido em: 01/06/2019 e aprovado em: 15/06/2019

\section{Notas}

1 O impeachment da presidente Dilma Rousseff, ocorrido no final de agosto de 2016, caracterizou-se como uma ação antidemocrática de derrubada de um Governo que foi eleito legitimamente e que vinha, processualmente, constituindo ações governamentais em prol da melhoria de uma série de dimensões e condições de vida dos brasileiros, reduzindo as diferenças gritantes e históricas das várias camadas sociais do País, a fim de constituir uma sociedade mais justa, igualitária e menos excludente, valorizando em maior destaque, por exemplo, diversas políticas públicas na área da educação. Esse impeachment, por sua vez, deu poder a um Governo ilegítimo, assumido por Michel Temer, que veio instituir ações, em maioria, com perfil neoliberal e excludentes, que se expressaram por frequentes reduções dos espaços de diálogo e constituição de uma sociedade pautada na defesa da democracia. Como exemplo pode ser mencionado a homologação da BNCC, que em sua fase final de elaboração se expressou de modo autoritário, sem debates com os mais diversos órgãos, instituições e entidades educacionais do Brasil, desvalorizando o trabalho de discussão anteriormente realizado em prol da elaboração deste documento.

2 Este documento, conforme sua tramitação atual no CNE, tem como relator o Conselheiro Mozart Neves Ramos.

3 As oito entidades que assinaram o manifesto foram: ABdC, Abrapec, Anfope, Anpae, Anped, Cedes, Fineduca e Forumdir.

4 A retomada desse enfoque - cuja lógica situa os profissionais da educação como corresponsáveis pelo desempenho dos alunos, a considerar a composição atual do CNE, em particular a presença de Maria Helena Guimarães de Castro, não pode ser negligenciada. Vale lembrar que no período que integrou o Inep ela compôs a equipe responsável por implementar o Exame Nacional do Ensino Médio (Enem), o Sistema Nacional de Avaliação da Educação Básica (Saeb), o Exame Nacional de Cursos (conhecido como Provão) e o Sistema Nacional de Informação Educacional. Em 2017, à época Secretária Executiva, Maria Helena já manifestava alinhamento a ideia da responsabilização dos professores sobre o desempenho escolar. Hoje, ela e uma parcela da equipe do MEC que elaborou a "nova" PNFP têm assento no CNE.

5 A ABdC, Abrapec, Anfope, Anpae, Anped, Cedes, Fineduca e Forumdir foram as entidades consultadas.

6 Um exemplo é a ideia de que “o magistério é a base da formação", incorporada ao artigo 67 da LDB nº 3.934/96 nos seguintes termos: “A experiência docente é pré-requisito para o exercício profissional de quaisquer outras funções de magistérios nos termos das normas de cada sistema de ensino" (ALVES, 2017, p. 6).

\section{Referências}

AGUIAR, Márcia Ângelada Silva. Relato da resistência à instituição da BNCC pelo Conselho Nacional de Educação mediante pedido de vista e declarações de votos. In: ; DOURADO, 
Luiz Fernandes. (Orgs.). A BNCC na contramão do PNE 2014-2024: avaliação e perspectivas. Recife: ANPAE, 2018, p.8-22.

ALVES, Nilda GUIMARÃES. Formação de docentes e currículos para além da resistência. Revista Brasileira de Educação, Rio de Janeiro, ANPED, v. 22, n. 71, p.1-18, 2017.

ANPED. Posição da ANPEd sobre a questão da Formação Inicial e Continuada de Professores e seu marco legal Resolução CNE /CP no 2, de 1 de julho de 2015. Posicionamento apresentado ao CNE em audiência realizada em Brasília no dia 06 de maio de 2019 (mímeo).

Nota sobre a Base Nacional Comum para Formação de Professores. Publicada em 21/12/18 na página institucional da entidade. Disponível em: $<\mathrm{http}: / /$ www.anped.org.br/news/nota-sobre-basenacional-comum-para-formacao-de-professores $>$. Acessado em: 01 maio 2019.

. Manifestação das entidades educacionais sobre a política de formação de professores anunciada pelo MEC. Publicada em 20/10/17 na página institucional da entidade. Disponível em: $<$ http://www.anped.org.br/news/manifestacao-das-entidades-educacionais-sobre-politica-deformacao-de-professores-anunciada>. Acessado em: 01 maio 2019.

BRASIL. MEC. Proposta para Base Nacional Comum da Formação de Professores da Educação Básica. Brasília, 2018. Disponível no endereço: <http://portal.mec.gov.br/index.php?option=com_docm an\&view=download\&alias=105091-bnc-formacao-de-professores-v0\&category_slug=dezembro-2018pdf\&Itemid=30192>. Acessado em: 01 maio 2019.

Política Nacional de Formação de Professores. Brasília: 2017 (slides apresentado por Maria Helena Guimarães de Castro). Disponível em: <http://portal.mec.gov.br/docman/outubro-2017pdf/74041-formacao-professor-final-18-10-17-pdf/file>. Acessado em: 01 maio 2019.

CABRAL NETO, Antônio; RODRIGUEZ, Jorge. Reformas Educacionais na América Latina: cenários, proposições e resultados. ; CASTRO, Alda Maria Duarte Araújo; FRANÇA, Magna;

QUEIROZ, Maria Aparecida de. (Orgs.). Pontos e Contrapontos da Política Educacional: uma leitura contextualizada de iniciativas governamentais. Brasília: Liber Livro Editora, 2007, p. 13-50.

DOURADO, Luiz Fernandes. Plano Nacional de Educação: O epicentro das políticas de estado para a educação brasileira. Goiânia: Editora da ImprensaUniversitária/ANPAE, 2017.

. Diretrizes Curriculares Nacionais para a Formação Inicial e Continuada dos profissionais do magistério da Educação Básica: concepções e desafios. Educação e Sociedade, Campinas, CEDES, v. 36, n. 131, p.299-324, abr.-jun., 2015.

FARIAS, Isabel Maria Sabino de; BEZERRA, José Eudes Baima. Do documento ao documento: recompondo seu lugar histórico. In: NÓBREGA-THERRIEN, Silvia Maria; FARIAS, Isabel Maria Sabino de; NUNES, João Batista Carvalho. (Orgs.). Pesquisa científica para iniciantes: caminhando no labirinto. Métodos de pesquisa. Fortaleza: EdUECE, 2011, p.43-53 (Vol. III).

LOPES, Alice CASIMIRO. Apostando na produção contextual do currículo. In: AGUIAR, Márcia Ângela da Silva; DOURADO, Luiz Fernandes (Orgs.). A BNCC na contramão do PNE 2014-2024: avaliação e perspectivas. Recife: ANPAE, 2018, p.23-27.

MACEDO, Elizabeth. "A base é a base". E o currículo o que é? In: AGUIAR, Márcia Ângelada Siva; DOURADO, Luiz Fernandes. (Orgs.). A BNCC na contramão do PNE 2014-2024: avaliação e perspectivas. Recife: ANPAE, 2018, p.28-33.

MAIS UMA VEZ CONVOCADOS. Manifesto ao povo e ao Governo. Manifesto de educadores brasileiros escrito pelo prof. Fernando de Azevedo. Revista Brasileira de Estudos Pedagógicos, Brasília, INEP, v. XXXI, n. 74, abril/junho, 1959, p.3-24. 